\title{
Profit-oriented Impact Analysis of Demand Management Strategy on Design-Build Firms Using System Dynamics
}

\author{
Yoo, Wi-Sung \\ Construction Management Division, Construction \& Economy Research Institute of Korea, \\ Gangnam-Gu, Seoul, 135-701, Korea
}

\begin{abstract}
In the past, a strategic management of work demands has been increasingly challenged to design-build (DB) firms. Such a management is capable of providing sufficient profitable impact of a project on them. Total project profit is mainly related to actual resources, work completion time, amount of rework, and costs. The degree of recycling work packages in the $\mathrm{DB}$ project delivery system is used as a measure of the quality of the performed work. However, there are few models available to evaluate the impact of a demand management strategy on the DB firms and to predict its behavior. We propose a decision-making support model as an aid for assessing the amount of rework and for predicting project profit resulting in a convincible demand management strategy. This model is constructed by using a dynamic feedback approach that can analyze the problems arising in complex managerial systems. For the purpose of illustration, widely acceptable strategies were applied into the model to explore their impacts on the DB firms. The results indicate that the model is helpful for the managers in selecting the most appropriate demand management strategy for successfully achieving their objectives.
\end{abstract}

Keywords : design-build firms, demand management strategy, dynamic feedback approach, rework, total project profit

\section{Introduction}

Many industries are continually impacted by the increasing competitions, which often raise the standards of quality and service for a given price. One way that the construction industry has responded to the competitions is through the creation of design-build (DB) firms. A DB firm integrates construction contractors, design engineers and architects, and material suppliers to make a team capable of addressing project concerns more quickly and effectively[1,2,3]. The DB project delivery

\section{Received : September 5, 2011}

Revision received : October 28, 2011

Accepted : October 31, 2011

* Corresponding author: Yoo Wi-Sung

[Tel: 82-2-3441-0860, E-mail: wsyoo@cerik.re.kr]

(c)2012 The Korea Institute of Building Construction, All rights reserved. system, as a favored system that significantly impacts on the service-supply chains, has gained more importance in recent years for potential advantages in improving project performance[4,5]. Construction projects using the $\mathrm{DB}$ delivery system have frequently outperformed those using the design-bid-build (DBB) in terms of schedule, change, rework, and practicability[6]. Also, the DB is effective for large-scale or highly complex projects unlike the DBB minimizing the risk through the control of design and construction processes[7,8,9].

In delivering a construction project, rework is defined as an unnecessary effort of re-doing a process or task that was incorrectly implemented at the first time[10]. Delays from rework can be reduced through the increased cooperation between designers and constructors. The performance of the DB process is important to the owner of a facility 
to be constructed and to the managers involved in the project delivery[11]. The owner desires the greatest value of the investment, while the managers pursue a management policy that works to maximize profit for the firm[12,13]. A management-related response to work demands of the DB firms influences on the work flow of the service-supply chain. However, such a response in project delivery system can be unknown because of the characteristics of diverse demand management strategies. There are many internal and external factors influencing on the project execution, which can be managed to improve project quality[14]. With the unforeseen circumstances in executing a project, it is difficult for managers to predict accurately the work flow in delivering a said project. For this reason, they have used historical data in attempts to find an improved method of effectively modeling the supply chain system. To maximize the profit, managers utilize a systematical modeling process to predict dynamic changes affecting the work flow.

With the implementation capability of a DB firm, demand management is an important strategy for meeting and controlling the works required by the customer or market. This can be directly related to a service-supply chain plan fitting the capacity that a DB firm accomplishes the cost-effectiveness, the shortened completion, and the value-based quality improvement. As well, a strategic demand management is one of important elements to achieve the maximum profit of a DB firm. This study applies the demand management strategies described by Crandall and Markland[15] into a dynamic feedback model, and analyzes impacts of each strategy on the DB firms. These strategies have been used to service-supply chains in many sectors, such as manufacturing process, construction, and design. They embrace a wide range of the potential issues in service industries involving the importance of demand or capacity management. In this study, system dynamics (SD) approach, which is useful for developing high quality dynamic feedback models, has been utilized to build a preliminary model to explore and explain the profit-oriented impact generated by a demand management strategy on the DB firms.

\section{Objective and scope}

The DB firms usually undergo either periods of excess demand resulting in insufficient capacity to perform project work packages at the desired quality and pace, or of excess capacity that causes higher costs because of unnecessary overhead[16,17]. The DB managers need a suitable demand management strategy to achieve the goal of maximum profit, which is affected by any additional overhead incurred by using a certain demand management strategy. Meanwhile, the level of the provided service affects the value of the owner' $\mathrm{s}$ investment and the firm' $\mathrm{s}$ reputation[18,19]. It is difficult to determine the relationship between demand management strategies and performance of a project delivery system because of the complexities of service-supply chain behaviors coupled with the adjustment of resource capacity. The model provided in this study is concerned with four demand management strategies, which are called Provide (S1)', 'Control (S2)', 'Influence (S3)', and 'Match (S4)'. Crandall and Markland[15] have stated that these strategies are sufficiently convincible for explaining the unknown relationship existing between a design-build service-supply chain and a demand management strategy. They are described by a specific characteristic as follow:

- S1 sustains a capacity to provide for peak demand at all times. 
- S2 attempts to maintain a capacity at a constant level that is sufficient to meet the service level desired by the customers.

- S3 affects customer' s demands to coordinate more closely to the current capacity.

- S4 matches to a supply as close as possible to demands.

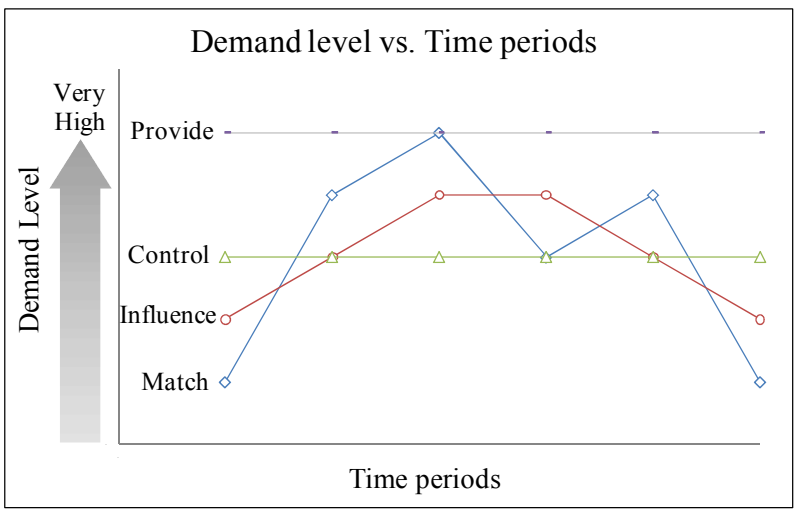

Figure 1. Demand level of S1, S2, S3, and S4 strategies

All strategies deal with managing work capacities to meet a demand, and their fundamental plots is shown in Figure 1. The S1 and S2 strategies resist the change of the capacity over time. The S1 strategy focuses more on customer' s satisfaction and sustained quality to enhance the firm' $\mathrm{s}$ service reputation, while the S2 strategy seeks the reduced overhead by meeting the average demand. The S3 and S4 strategies vary the capacity over time to meet a demand. The S3 strategy relies on marketing strategies such as promotions, pricing, and other techniques to bring demand closer to current capacity. The S4 strategy requires the forecast of a demand and close affiliation with other service providers that may be subcontracted temporarily[20]. This study includes two main objectives. One of them is to analyze the relationship between a demand management strategy and a behavior of design-build service-supply chain accumulation. The other is to develop a model capable of explaining and predicting the profit-oriented impact of each strategy on the DB firms. These can assist to the DB managers in establishing an effective demand management strategy and in increasing the benefits for both the customer and contractor. Such a model is constructed under the considerations of design-build service supply chain, error generation and rework, and resource and demand management strategy with a few rational constraints. A diversity of causal factors in the model is assembled from literature reviews[10,21, $22,23]$ since exploring the general characteristics of the DB projects. Their causal relationships are interrogated through the interviews with senior project managers who have sufficient experience of the DB projects. In this study, a preliminary model using the SD is developed to analyze the profit-oriented impact of a demand management strategy responding the works available to a DB. Such a model is mainly based on the expert' $\mathrm{s}$ qualitative and subjective opinions because a demand management strategy and a supply chain service plan are complicated and mutually related in the unforeseen environment. As well, this model is not only concerned with a specified type, size, and complicatedness of a $\mathrm{DB}$ work in the domestic or international application.

\section{Model development}

\subsection{System dynamics (SD)}

The SD has been utilized for analyzing a variety of policy alternatives and for developing a systematical replication of reality, serving as an analysis tool for making a strategic decision in construction management executives. Through multiple feedback loops, the SD is especially helpful to reflect the behaviors of large-scale 
construction projects that involve a variety of changes over time because of being extremely complex and highly dynamic. One of the most powerful features is its capacity to provide analytic solutions for both complex and nonlinear systems[24]. The multiple feedback loops consist of variables that are connected by arrows denoting the causal influences between variables. A causality link can be considered as positive or negative, represented by plus and minus signs. A positive link between two variables implies that they tend to move in the same direction of change. For example, if an increase (decrease) in a variable leads to increase (decrease) in another variable, then the type of causality is positive. Otherwise it is negative. Similarly, a negative feedback loop is a stability-seeking loop, and its movement directs a system back to the starting. A positive feedback loop generates growth, not equilibrium as in a negative feedback loop.

Ogunlana et al.[25] have demonstrated the capability of the SD to simulate and optimize a complex system with qualitative information. Further details of the SD approach can be found in Richardson and Pugh[26]. The main previous studies in terms of the applications of the SD into construction projects are tabulated and explained in Table 1. In this study, the SD is used for building a design-build service-supply chain model (DBSSCM), which is expanded to a few components to estimate the firm' $\mathrm{s}$ profit, given a certain work demand and management policy. Rework, error generation, resource, demand management strategy, and profit component are connected to the DBSSCM; each component has its own basis and constraints used for validation.
Table 1. Previous studies on the application of the SD to construction projects

\begin{tabular}{|c|c|c|}
\hline & Related researches & Major outcomes \\
\hline Domestic & $\begin{array}{l}\text { - Lee et al. (2007) [9] } \\
\text { - Kim et al. } \\
\text { (2007) [22] } \\
\text { - Park et al. } \\
\text { (2009) [29] }\end{array}$ & $\begin{array}{l}\text { - Analysis of characteristics } \\
\text { of DB delivery system } \\
\text { - In-depth analysis and } \\
\text { cultivation of a supply } \\
\text { demand forecasting } \\
\text { system } \\
\text { - Causal loop and } \\
\text { sensitivity analysis of } \\
\text { policy scenarios }\end{array}$ \\
\hline International & $\begin{array}{l}\text { - Ogunlana et al. } \\
\text { (2003) [25] } \\
\text { - Richardson and } \\
\text { Pugh (1987) [26] } \\
\text { - Nasirzadeh et al. } \\
\text { (2008) [27,28] }\end{array}$ & $\begin{array}{l}\text { - Generic system to develop } \\
\text { the relationships inherent } \\
\text { in DB project } \\
\text { - Proposing and testing } \\
\text { hypothetical DB policy } \\
\text { alternatives to enhance } \\
\text { DB performance } \\
\text { - Analyzing the effects of } \\
\text { strategic policies on the } \\
\text { performance enhancement } \\
\text { of a construction firm } \\
\text { - Potential capability of the } \\
\text { SD in the application to } \\
\text { the construction industry } \\
\text { - Building an integrated } \\
\text { model for analyzing } \\
\text { the risk of a construction } \\
\text { project }\end{array}$ \\
\hline
\end{tabular}

\subsection{Design-build service-supply chain model}

Project delivery system originated from new works provided by a customer is started and ended when the works are completed. In the SD approach, the stock through the system is defined as a work package. Total available works enter to the market on the basis of customer demands and then part of them become available to the $\mathrm{DB}$ firms. The DBSSCM is operated for a DB firm until the contracted work is completed. The probability of receiving the works affects how much work is contracted to the firms. For simplicity, the probability was set to 1 while validating the DBSSCM. A service-supply chain model includes the design and construction sections of a DB firm. These sections are represented by the stock variables with the work in design and construction, as shown in Figure 2. The flow of work packages 


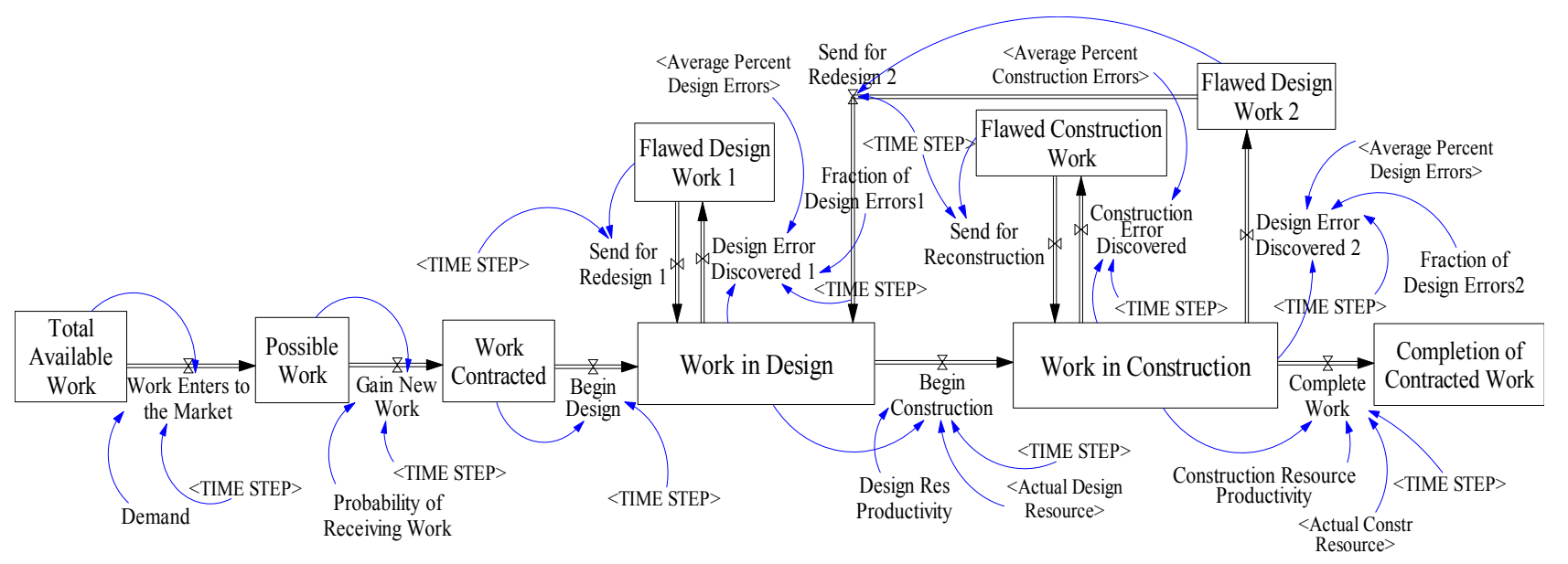

Figure 2. Design-build service-supply chain model (DBSSCM)
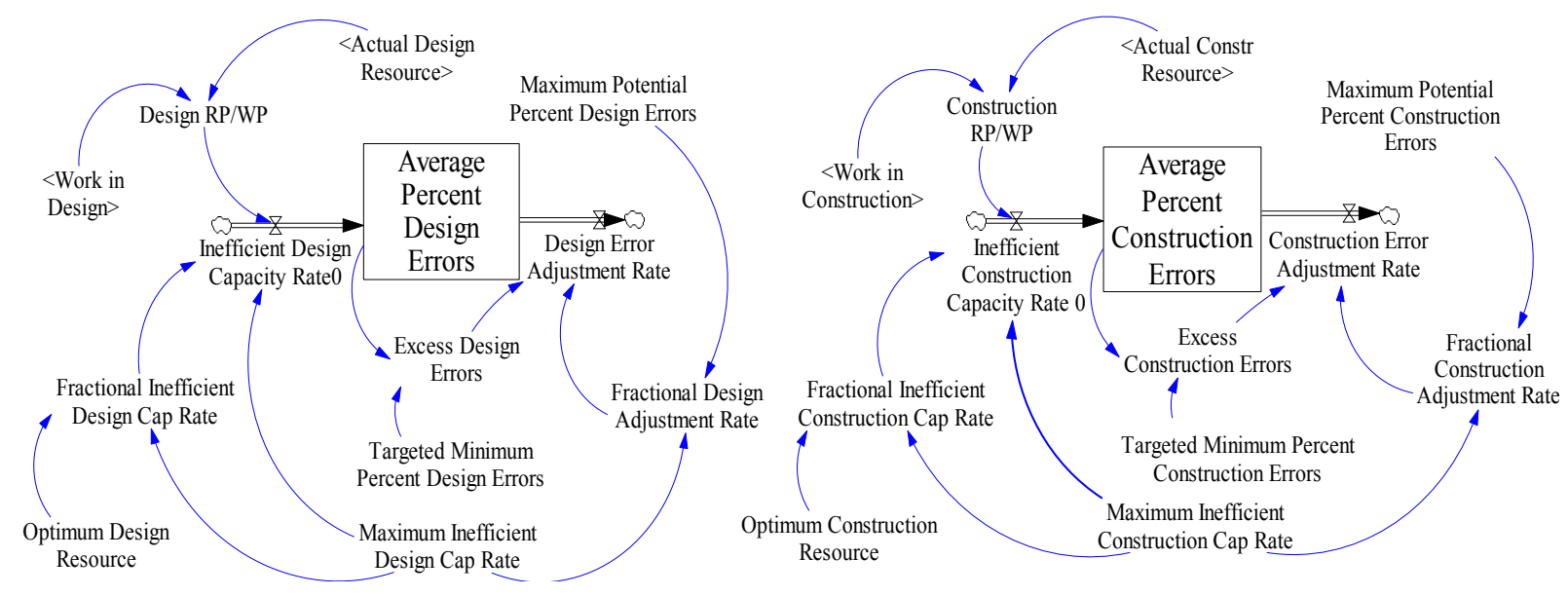

Figure 3. Error generation component

changes depending on the contracted works, the amount of resources, the productivity, and the amount of reworks in the design and construction phases. There are several constrains to simplify and understand the DBSSCM easily. In a DB firm, construction phase starts even though entire engineering design has not been completed. In this model, it is assumed that work packages cannot be constructed until they are designed and that the design and construction resource productivity is assigned as 0.1 work packages per week. This is an arbitrary estimate for the productivity rate of a general DB firm.

\subsection{Rework component}

Rework resulting from designers and constructors is represented by the recycling' work that occurs between the service-supply chains. There are two types of errors to incur rework; only design errors during the design phase and both design and construction errors during the construction phase. To investigate the amount of rework during the execution, it is important to understand the factors that influence the behavior of rework. One factor is how many design errors are discovered while the work is in design or construction. They are determined by error generation component that provides an average 
percent of design errors. As shown in Figure 3, the rate of design errors is found by the fraction of design errors and average percent design errors variables. As a project is in the construction stage, rework can occurred by wholly construction-related errors and errors that were not discovered during the design stage. The amount of entire rework is indicated by the rate of the discovered design and construction errors. For the purpose of illustration, it is supposed that 80 percent of design errors are discovered during the design phase and that the remaining 20 percent are found in the construction phase.

\subsection{Error generation component}

The percentage of errors found in the design and construction phases can be used as an indicator to measure the provided quality for a given project. To maximize a profit, a DB firm tends to seek strategies to minimize the number of errors incurred. This reduces the amount of rework with a certain amount of resources allocated in each activity to be achieved, and leads to the reduction of project cost and duration associated with rework.

It seems that obtaining as many resources as possible contributes to the better quality and the reduction of total duration. However, more resources in a project require the higher costs. For this reason, it is important to optimize the amount of resources and it is considerable to investigate how the certain amount of resources allocated using different demand management strategies can affect the amount of the incurred reworks and cost and duration to complete a project.

The discovered error rate is determined by the trend of average percent errors. The goal of developing an error generation component is to explore the behavior of a tendency of the average percent errors, which affect the amount of works

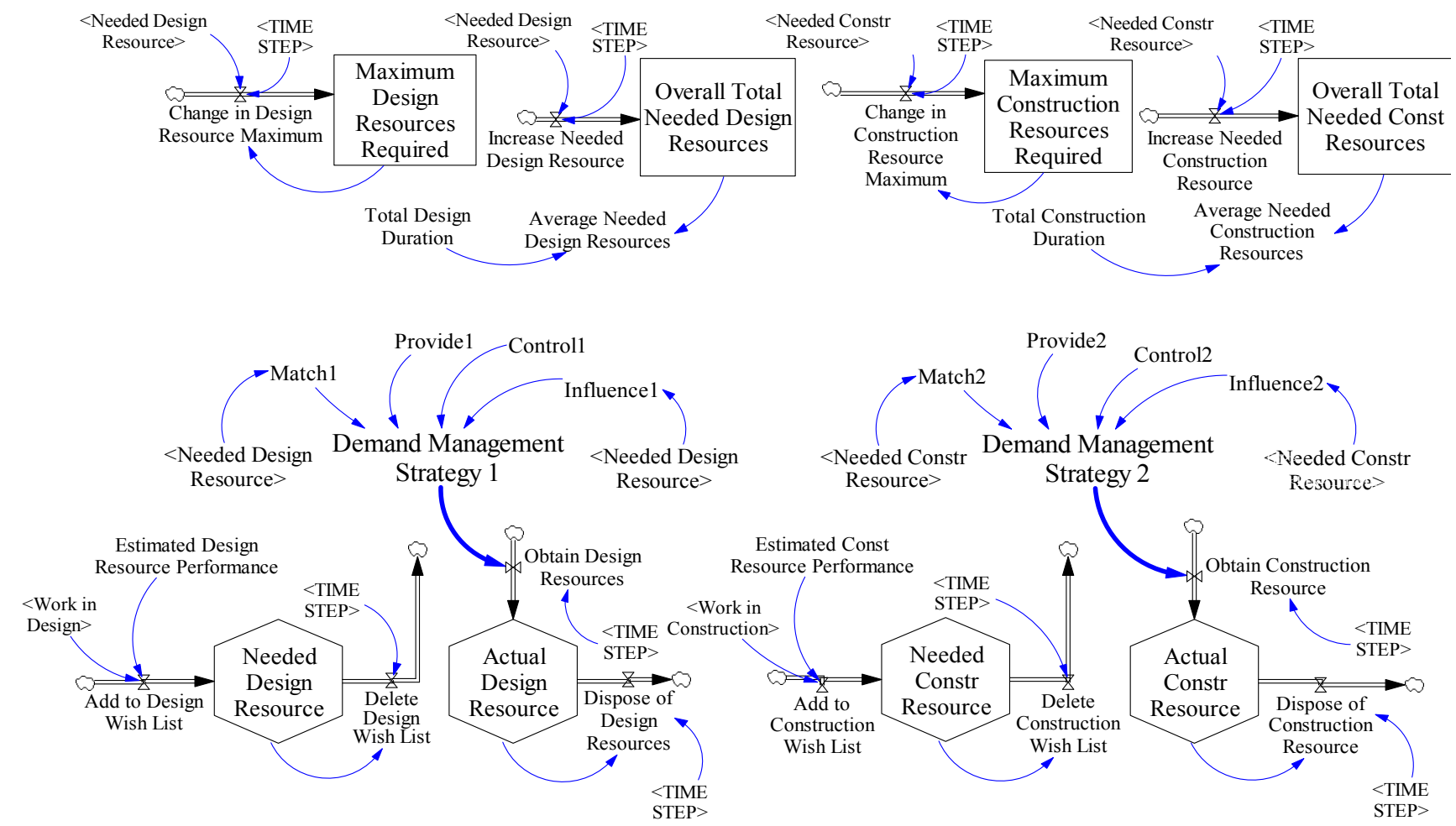

Figure 4. Resource and demand management strategy component 
that have to be redone. Given the actual resource variable residing within the component, the resource variables are indicated as the number of resource packages $(\mathrm{RP})$ used to complete one work package (WP), referred to as RP/WP. The reason that this ratio has to be used in deriving average percent errors is because an increase in the amount of work is not proportionally enhanced with an increase in the amount of total resources. In this study, it is assumed that every error incurred during the design or construction phase can be discovered.

As the number of resources per work package fluctuates over the execution, the percentage of errors varies from the targeted minimum to the potential maximum. In this component, it is also constrained that the maximum percentage of errors that can possibly occur is set to 20 percent, whereas the targeted minimum percentage with the sufficient available resources is set to 1 percent in both the design and construction phases. As the amount of resources greatly exceeds to the actually required amount, especially in construction phase, the site congestion tends to increase. This also leads to a decrease in work capacity and results in a greater percentage of work errors. Since building the error generation component, the DBSSCM is validated by the simulation to assess whether the intended representation of average percent errors against resource packages per work package is generated.

\subsection{Resource component}

A resource component is used to estimate a needed amount of resources on the basis of the workload. A demand management strategy to adjust the actual resources is derived from the needed resources generated by the simulation. In Figure 4, separate components are created for design and construction resources because the $\mathrm{DB}$ firm tends to have different resource requirements. The design section uses a demand management strategy different from that of the construction section. It is expected that the design and construction sections also have a differently estimated resource performance value because of the different types of works. An estimate of resource performance can come from the experienced members of the DB firms, who can determine the workload to estimate the amount of the needed resources on the basis of their experience-based knowledge from the previously related works. Then they select a demand management strategy and adjust the amount of actual design and construction resources. In this study, it is supposed that the resource performance is set to a different value, which is qualitatively presumed by the senior experts with the sufficient experience in DB works. A gap exists between the needed and actual resources because of the changes in the workload. In this component, design and construction resource performance are set at 10 resource packages per work package during a week. The component is implemented by keeping operations moving over a time step of one week.

\subsection{Demand management strategy component}

A demand management strategy is utilized to control the rate of obtaining resources. To determine this rate, each strategy has used the estimated value of the needed design resources. The rate in the S4 strategy is derived from the difference between the needed and actual resources. Thus, the actual resources are always made to match the needed resources. The S3 strategy influences the demand to coordinate more closely to the current capacity.

The marketing strategy and firm's reputation influencing the demand need to be added to the 


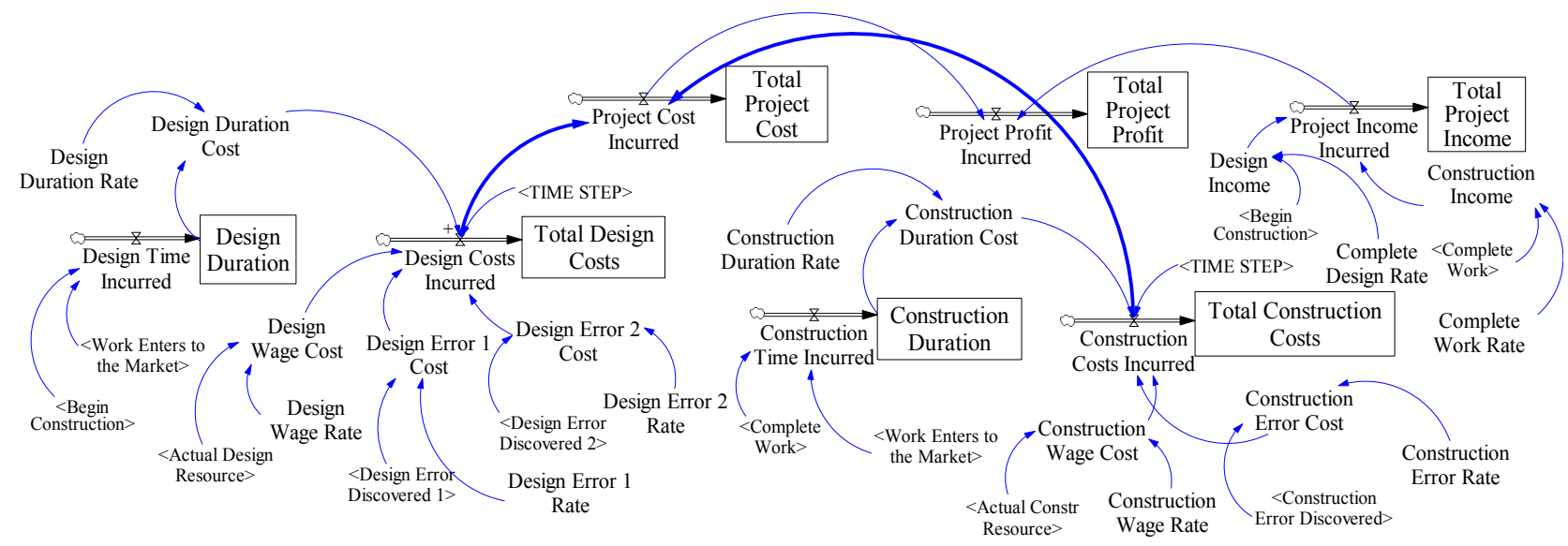

Figure 5. Profit component

component in order to appropriately reflect the S3 strategy. However, in this study, it is assumed that this strategy is modeled by smoothing function over 10 weeks for less variation in the demand.

The S2 strategy attempts to sustain the capacity at a constant level that is sufficient to meet the customers' expectation. Thus, the average amount of the needed design resources has to be calculated for the use of the S2 strategy. Likewise, the maximum amount of the required resources has to be recorded for the use of the S1 strategy. To discover the maximum value of the required resources and average needed design resources, the S4 strategy is simulated and the results are recorded. This study has applied four strategies by simulating with a qualitative information in terms of the needed against actual resources for a given demand through a preliminary model called the DBSSCM.

\subsection{Profit component}

As shown in Figure 5, a profit component is utilized to investigate the relations between demand management strategies, incomes, possible costs incurred from resources, completion time, and rework. To calculate the profit from a given project, cost is subtracted from income. In this component, the cost is separated by the design and construction cost sections, which are influenced by project duration and wage rates of resources. The income is affected by the work completion rate and the paid cost for each completed work package. In operating the component, design and construction completion rate are attempted by experimental values for the simulation, which are derived from the subjective and qualitative data of the experts. They must be further developed with the practical data in the analytical model. Design cost is calculated from design duration multiplied by a design rate. Design duration is represented by a stock of the incurred design time and supposed to be estimated by using the rates that a work enters the market and construction begins. The actual design resources and errors discovered from the design and construction phases also affect total design cost. Each resource has an associated wage rate that is estimated for the simulation. The summation of design and construction cost equals total project cost. For the purpose of illustration, design and construction duration rates are presumed by the same values; however, it is likely that the rates can be different in reality. Meanwhile, construction wage rate is probably higher than design wage 
rate because construction generally needs more resources in the form of equipment and labor. Love and Edwards (2004) has researched that design errors are occurred about 10 15\% more frequently than construction errors. In the preliminary model, design error rate is plenty assigned to a work package and set to 1.5 times of construction error rate.

\section{Model operation}

In this study, the DBSSCM connected with the aforementioned components is simulated to illustrate characteristics of each component and to explore interaction between a diversity of causal factors. The outputs are capable of answering to how applying S1, S2, S3, or S4 strategies into a DB firm affect to possible cost, income, and profit. They are used to discover the relationship between demand management strategies and the backlog of work packages flowing through the $\mathrm{DB}$ delivery system. Also, they provide an insight into how a demand management strategy affects to the backlog rate. The simulation of the resource component is implemented to explain how the amount of resources allocated by a selected strategy can differently influence the amount of work packages in the design and construction phases. The outputs from error generation and estimation of backlog rates of work packages can indicate how the selected strategy satisfies demand of the needed resources. Each demand management strategy is compared with a few main outputs: the discovered errors during the execution, total project cost, income, and profit.

Since simulating error generation component depending on resources successfully, the next step is to attach this component to the DBSSCM to investigate and understand the impact of the amount of the discovered errors on reworks. The stocks of total initial and final work in the DBSSCM are experimented to track the amount of works after the completion. This operation is capable of explaining the works in supply chain that cannot be created or destroyed during the execution.

With the integrated model, the actual amount of resources in both design and construction phase are determined by each demand management strategy. The resources used with the S1 strategy are the values that meet the peak demand over a project execution period, whereas the resources used with the S2 strategy are designed to meet the average demand. Because the S4 strategy attempts to vary resources to meet the varying demand, the simulation influenced by the strategy has to be run firstly. This strategy provides the amounts of the required maximum and average resources that are needed to plug into the $\mathrm{S} 1$ and S2 strategies, respectively. Next, the model behavior with each different strategy is investigated by simply changing the equations of the DMS1 and DMS2 for the design and construction phase, which indicate demand management strategies 1 and 2 in Figure4. Finally, the profit component provides the cost and duration incurred during the execution, which allow the managers to understand how a demand management strategy impacts on the profit. For an effective illustration, the outputs from the S4 strategy are mainly explained in the later.

\section{Result explanation}

\subsection{Needed and actual design resources}

As shown in Figure6, actual design resource, average percent errors, and total initial and final work were set for the simulation. In this study, it 

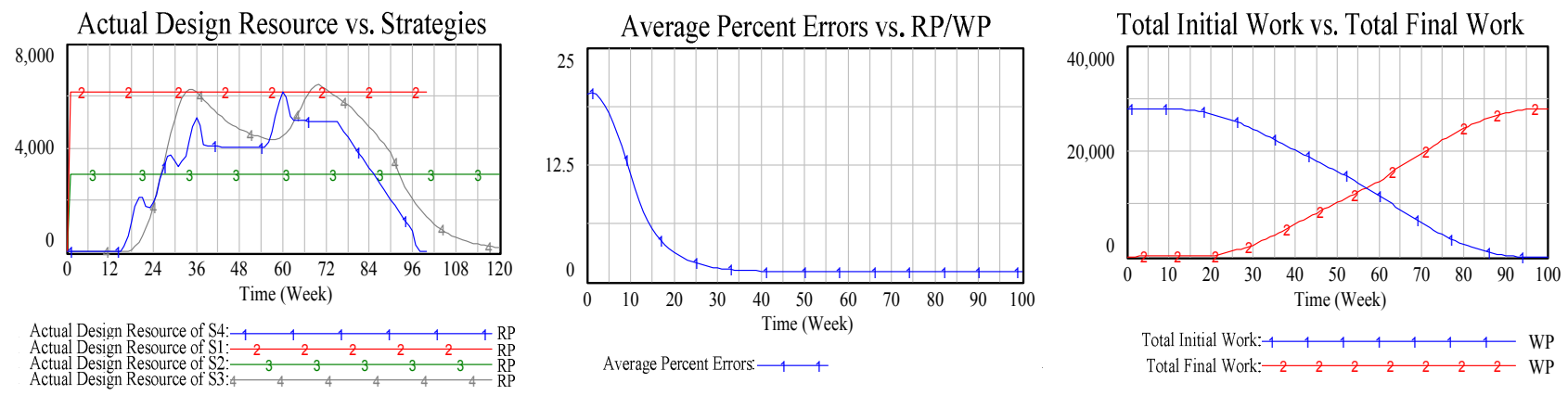

Figure 6. Actual design resource, average percent errors, and total initial and final work for the simulation

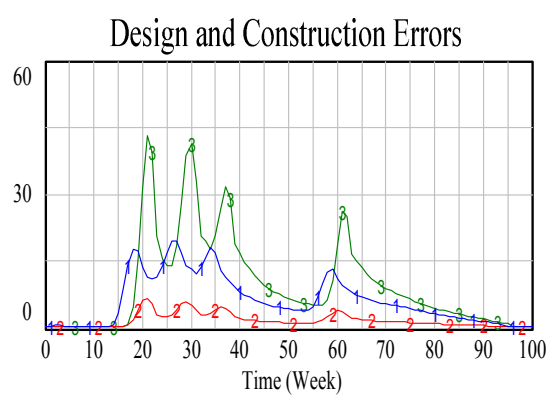

Design Errors in Design Phase of St:- $1,1,1,1,4$ WP/Week Design Errors in Constr. Phase of SH:2 $\begin{array}{lllll}2 & 2 & 2 & 2\end{array}$ WP/Week Constr. Errors in Constr. Phase of S4:- $\begin{array}{ccccc}- & 3 & 3 & 3 & 3\end{array}$ WP/Week
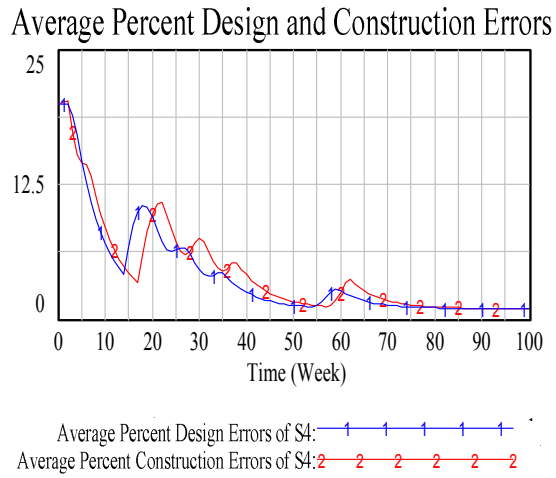

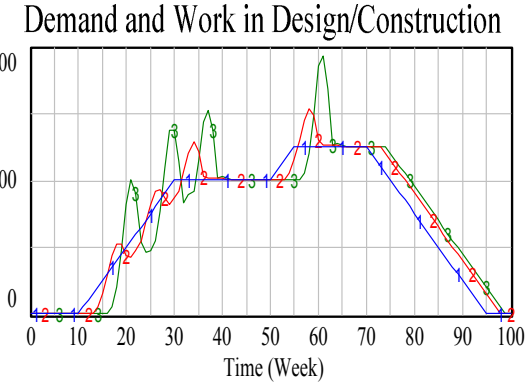

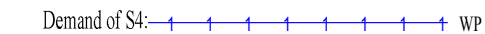
Work in Design of S4: $\frac{1}{2}{ }_{2}{ }_{2} 2_{2}{ }_{2}{ }_{2}{ }_{2} 2_{2}{ }_{2}$ WP

Figure 7. Average percent design and construction errors, design and construction errors, and demand and work in design and construction of the S4 strategy

was expected that resource demand with four aforementioned strategies completely reflect the practical use of the model. The S4 strategy has attempted to optimize the amount of actual resources to meet the varying work in design and construction plus errors incurred during the execution. The resources for the S1 strategy were constant and provided enough resource capacity to deal with the peak demand. Project duration using both strategies was similar because the needed resources to perform the work in the service-supply chain were always proper over time. Whereas, while applying the S2 strategy, the actual resource was equal to the average resource demand dealing with work package plus errors incurred. Hence, a project has taken a longer time to complete it when using the S2 strategy. The S3 strategy has attempted to smooth the actual resources by reducing the variation. The result from this strategy was smoother than that the S4 strategy by shifting the curve slightly forward.

\subsection{Average percent design and construction errors}

The percentage of errors has reduced with an increase in the amount of resources per work package. This can be explained by the fact that as insufficient resources are allocated to a project, there is an increase in mistakes; whereas, at the certain amount of resources, the participants tend to share their expertise and information throughout the team more efficiently to reduce errors. However, the percentage of errors has not reached zero percent error for every strategy due to the continuously changeable amount of 
resources per work package. This was because even though a project had practically excellent performance resources or had the resources over the required amount, there was still the possibility that errors occur.

The result from the S1 strategy showed that average percent errors smoothly decreased as the work package backlog flowed in the service-supply chain. This was because the amount of actual resources available stayed constant over time and it also has met the maximum of the needed resource demand per work package. For the S2 strategy, the percent of design errors diverted to continuously increase after the work package flowed to the work in design. This might be explained by the fact that the amount of work entering into the design phase kept growing while the resource capacity was still steady at the average resource demand. However, average percent errors by the S4 strategy has rapidly decreased at the beginning and then presented zigzag decreases, as shown in Figure7. It was expected that this behavior was resulted from a beneficial feature that the S3 strategy has timely adjusted the resource demands.

\subsection{Design-build service-supply chain}

According to an applied strategy, the different amount between the needed and actual resource was explored through the simulation. The behavior of the service-supply chain fluctuated with time in the response to changes in demand. In adjusting the work in design and construction, the backlog rate of flow of the service-supply chain by the S1 strategy was higher than those resulted from other strategies. Since the capacity of the S1 strategy has satisfied maximum demand, the lowest amount of work errors were incurred throughout the service supply chain and the backlog rate of flow has moved more quickly through the model. The greatest amount of the backlog rate of flow was decreased by the S2 strategy. This was because this strategy only strived to meet average demand and kept the rate moving more slowly through the model. The rates resulted from the S3 and S4 strategies were behaved between the values by the S1 and S2 strategies. The S4 strategy had a varying backlog rate because the capacity was continuously adjusted to meet the work package plus the work errors incurred. The S3 strategy has produced a similar rate to that of the S4 strategy, but not as erratic because the S3 strategy has attempted to smooth the resource demand to more closely meet the capacity.

\subsection{Total project profit}

One measurement of project success can be conducted by estimating total project profit. This study has explored how different amounts of resources from a demand management strategy have affected to project duration and cost, which eventually impact on project profit. In Figure 8, the accumulative profits by four demand management strategies are represented.

Since utilizing the S2 and S4 strategies has resulted in completing a project faster, their accumulative profits have stopped growing earlier than those of other two strategies, and have ended at project completion date. They showed that using the S4 strategy contributed to earning the highest profit at the end of a project and completed it earlier than using the S1 and S3 strategies. This was because every available resource is completely utilized to perform the work. Even though using the resources with the S1 strategy has always met the demand and was expected to complete a project the fastest, total project profit has been lower than that of the S4 strategy because the amount of actual resources has unnecessarily exceeded the needed resources. 


\section{Total Profit vs. Strategies}

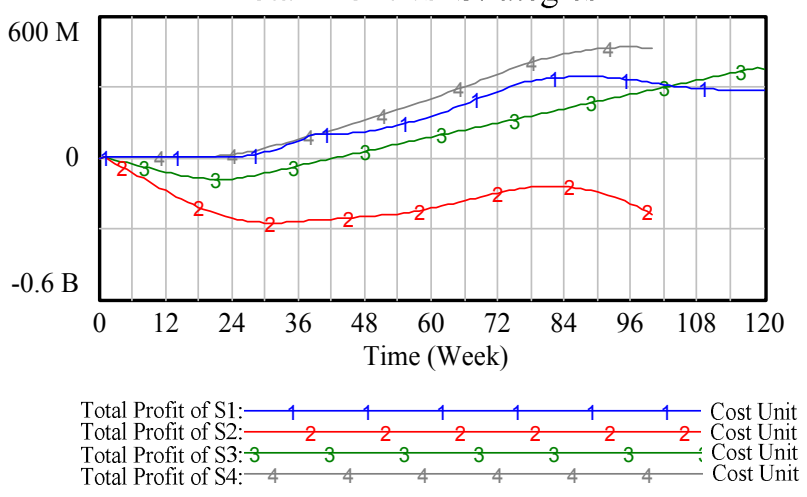

Figure 8. Comparison of total project profits

The S1 and S3 strategies have produced the similar profits at the end of a project. However, project income using the S2 strategy at the beginning was less than project cost. This can be explained by the fact that the amount of actual resources at the beginning is greater than the needed resources in reality.

\section{Conclusions}

In the presented DBSSCM, the application of four different demand management strategies was implemented to analyze their impacts on the $\mathrm{DB}$ firms. The results were compared by total project profit depended upon cost, duration, and resources. The S4 strategy provided the highest profit, but it was an idealized strategy. A project in the construction industry has been difficult to always have the timely proper resources. The S3 strategy was suggested to get a high profit for a DB firm. With a well-organized and capable management team, an effective strategy could be put into practice to produce positive outcomes. The S4 strategy has obtained the appropriate amount of resources and finished the project on time. Most firms are difficult to match exactly the needed resources because hiring and firing personnel is a complicated and costly job. The S1 strategy has produced the highest resource cost because the amount of actual resources was commonly higher than the needed resources. Maintaining more resources than the needed might negatively impact on a project profit, but it could be a realistic strategy implemented in an attempt to gain a good service reputation and to complete a project on time. The S2 strategy gave the highest error, longer duration, and more cost because of the shortage of actual resources. At the start, this strategy has resulted in a loss, and it seemed difficult to complete a project on schedule. Each strategy has their characterized advantages and disadvantages. The results of the presented model can be helpful as an aid for the manager in choosing the most appropriate demand management strategy that a DB firm utilizes for achieving its own specific objective. In other words, they provide the fundamental guidelines and help the DB firms establish a supply chain service plan to maximize an increasing profit with their own customized model.

\section{Limitations and further study}

The model introduced in this study may be difficult to apply at the detailed level, especially without the use of a computer program. Therefore, a preliminary model at the conceptual level has been constructed with many constraints in case that there is no enough reference to the outcomes between a cause and effect relationship. In this study, it was supposed that design-build works are continuously available to a DB firm, which can always adjust the service-supply chain according to the contracted works. However, the values for the qualitative simulation has been produced by the subjective judgments of the experts, and so 
they must be further developed with the practical data in the analytic and detailed model.

In the further, the effect of a demand management strategy on the prospect of receiving new work from the customer will be studied to expand the presented model. Thereby, a project manager will discover the most effective demand management strategy for increasing work demand. In addition, the model can be beneficially applied to the settings of different types of project delivery systems with manipulative customization processes. A customized model in the extensive environments reflects and counteracts flexibly a diversity of unforeseen and unexpected factors that may change the results of the preliminary model.

\section{References}

1. Booth WD. Marketing strategies for design-build contracting. 1st ed. New York (NY): Springer; 1995. 183 p.

2. Branca AJ. Cost effective design-build construction. Kingston, UK: R.S. Means Co.; 1987. 422 p.

3. Voss CA, Winch GM. Including engineering in operations strategy. Production and Operations Management. 1996 Mar;5(1):78-90.

4. Chritamara S, Ogunlana SO. System dynamics modeling of design and build construction projects. Construction Innovation: Information, Process, Management. 2002 Sep;2(4):269-95.

5. Park M, Ji SH, Lee HS, Kim W. Strategies for design-build in Korea using system dynamics modeling. Journal of Construction Engineering and Management. 2009 Nov;135(11):1125-37.

6. Thomas SR, Macken CL, Chung TH, Kim I. Measuring the impact of the delivery system on project performance-design-build and design-bid-build. National Institute of Standards and Technology. Texas (TX); 2002. p. 75-6.

7. Akintoye S. Design and build: a survey of construction contractor' s views. Construction Management and Economics. 1994 Apr;12(2):155-63.

8. Chan APC. Evaluation of enhanced design and build system a case study of a hospital project. Construction Management Economics. 2000 Oct;18(7):863-71.

9. Lee HS, Ji SH, Park M, Seong SH. Analyzing characteristics of design-build delivery system in Korea using system dynamics modeling. Korea Institute of Construction
Engineering and Management. 2007 Oct;8(5):119-32.

10. Love PED, Edwards DJ. Forensic project management: the underlying causes of rework in construction project. Civil Engineering and Environmental Systems. 2004 Jul;21(3):207-28.

11. Songer AD, Molenaar KR. Project characteristics for successful public-sector design-build. Journal of Construction Engineering and Management. 1997 Mar;123(1):34-40.

12. Booth WD. Design/build marketing. 1st. ed. New York (NY): Van Nostrand Reinhold; 1992. 188 p.

13. Roemer TA, Ahmadi R, Wang RH. Time-cost trade-offs in overlapped product development. Operations Research. 2000 Nov;48(6):858-65.

14. Platt DG, Blockley DI. A process support environment for design management. 1st. ed. New York (NY): Chapman \& Hall; 1995. p. 259-71.

15. Crandall RE, Markland RE. Demand management-today' $\mathrm{s}$ challenge for service industries. Production and Operations Management. 1996 Jun;5(2):106-20.

16. Pre-project planning research team. Pre-project planning handbook. Construction Industry Institute. Texas (TX); 1994. p. 15-6.

17. Cooper GS, Brandon P. Integrating points of view through information modeling. 1st. ed. New York (NY): Springer; 1995. p. 248-57.

18. Barr V. Promotion strategies for design and construction firms. 1st. ed. New York (NY): Van Nostrand Reinhold; 1995. $182 \mathrm{p}$.

19. Li L, Zhang $\mathrm{H}$. The multistage service facility start-up and capacity model. Operations Research. 2000 May;48(3): 490-97.

20. Moodie DR. Demand management: the evaluation of price and due date negotiation strategies using simulation, Production and Operations Management. 1999 Jun;8(2):151-62.

21. Hale DR, Shrestha PP, Gibson GE, Migliaccio GC. Empirical comparison of design/build and design/bid/build project delivery methods. Journal of Construction Engineering and Management. 2009 Jul;135(7):579-87.

22. Kim ST, Park MS, Lee HS, An SJ, Ryu HG. Supply-demand forecasting of principal engineers in construction industry using system dynamics. Korea Institute of Construction Engineering and Management. 2007 Oct;8(5):161-72.

23. Seng NGW, Yusof AM. The success factors of design and build procurement method: a literature visit. In: 6th 
Asia-Pacific Structural Engineering and Construction Conference; 5-6 September 2006; Kuala Lumpur, Malaysia. Rosemead (CA): Scientific \& Academic Publishing Co.; 2006. p. $\mathrm{C} 1-11$.

24. Sterman J. Business dynamics: system thinking and modeling for a complex world. 2nd. ed. New York (NY): McGraw-Hill; 2000. 993 p.

25. Ogunlana SO, Li H, Sukhera FA. System dynamics approach to exploring performance enhancement in a construction organization. Journal of Construction Engineering and Management. 2003 Sep;129(5):528-36.

26. Richardson GP, Pugh AL. Introduction to system dynamics modeling with dynamo [PhD dissertation]. Cambridge (MA): Massachusetts Institute of Technology; 1981. 278 p.

27. Nasirzadeh F, Afshar A, Khanzadi M. System dynamics approach for construction risk analysis. International Journal of Civil Engineering. 2008 Jun;6(2):120-31.

28. Nasirzadeh F, Afshar A, Khanzadi M, Howick S. Integrating system dynamics and fuzzy logic modeling for construction risk management. Construction Management and Economics. 2008 Nov;26(11):1197-212.

29. Park MS, Ahn CB, Lee HS, Hwang SJ. Analysis of the Korean housing market mechanisms and housing sales policies using system dynamics. Korea Institute of Construction Engineering and Management. 2009 Jun;10(3):42-52. 